\title{
An Integrated Energy-Efficient Operation Methodology for Metro Systems Based on a Real Case of Shanghai Metro Line One
}

\author{
Cheng Gong ${ }^{1}$, , Shiwen Zhang ${ }^{1}$, Feng Zhang ${ }^{1}$, Jianguo Jiang ${ }^{1}$ and Xinheng Wang ${ }^{2}$
}

1 Key Laboratory of Control of Power Transmission and Conversion, Ministry of Education, Shanghai Jiao Tong University, 800 Dongchuan Road, Shanghai 200240, China;

E-Mails: swzhang@sjtu.edu.cn (S.Z.); fzhang@sjtu.edu.cn (F.Z.); jiang@ @jtu.edu.cn (J.J.)

2 School of Engineering and Computing, University of the West of Scotland, Paisley PA1 2BE, Scotland, UK; E-Mail: xinheng.wang@uws.ac.uk

* Author to whom correspondence should be addressed; E-Mail: gongcheng0810@sjtu.edu.cn; Tel.: +86-136-0191-6871.

External Editor: Enrico Sciubba

Received: 17 July 2014; in revised form: 1 November 2014 / Accepted: 5 November 2014 / Published: 13 November 2014

\begin{abstract}
Metro systems are one of the most important transportation systems in people's lives. Due to the huge amount of energy it consumes every day, highly-efficient operation of a metro system will lead to significant energy savings. In this paper, a new integrated Energy-efficient Operation Methodology (EOM) for metro systems is proposed and validated. Compared with other energy saving methods, EOM does not incur additional cost. In addition, it provides solutions to the frequent disturbance problems in the metro systems. EOM can be divided into two parts: Timetable Optimization (TO) and Compensational Driving Strategy Algorithm (CDSA). First, to get a basic energy-saving effect, a genetic algorithm is used to modify the dwell time of each stop to obtain the most optimal energy-efficient timetable. Then, in order to save additional energy when disturbances happen, a novel CDSA algorithm is formulated and proposed based on the foregoing method. To validate the correctness and effectiveness of the energy-savings possible with EOM, a real case of Shanghai Metro Line One (SMLO) is studied, where EOM was applied. The result shows that a significant amount of energy can be saved by using EOM.
\end{abstract}


Keywords: metro system; energy-saving; energy-efficient operation methodology; timetable optimization; compensational driving strategy algorithm

\section{Introduction}

Nowadays metros systems are playing important roles in our daily lives, especially in large cities. In developing countries like China, dozens of metro lines have been built in large cities and more are going to be built in the next few decades. For example, in Shanghai, the metro system has a total route length of over $500 \mathrm{~km}$ and carries over 8 million people each day. By the end of 2020, the total route length will be more than $1000 \mathrm{~km}$ [1]. Since metro systems consume huge amounts of energy each day, saving even a few percent of the total energy can lead to great economic growth and environmental protection benefits. In the last few years, researchers have begun to pay more attention to finding the economic operation strategies for metro systems and have made some achievements.

González-Gil [2] provided a comprehensive appraisal of the main practices, strategies and technologies currently available to minimize the energy use of urban rail systems. In all these technologies, the two main methods are energy-efficient driving (eco-driving) and utilization of regenerative braking energy. The operation strategy of eco-driving is to optimize the speed profile of each train, while the utilization of regenerative braking energy is for one train to re-use the energy generated by the braking of other trains. The first topic has been well studied by many researchers [3-15], while the latter is a rather new approach. It is based on the practice that the acceleration process consumes energy from the power supply network whereas the braking process returns energy to the supply network. One way to use the returned energy from braking is to store the energy it generates. Up to now, several methods have been proposed to store the energy generated by braking, such as using supercapacitors [16-21], flywheels [22-26] and batteries [27-31]. An exclusive review of these technologies can be found in [32]. However, it is not easy to apply these methods in practice. On the one hand, high levels of capital investment are needed to build the new infrastructure. On the other hand, the implementation of the new infrastructure in and existing metro system is hard as well.

An alternative practical and economical approach to use the energy from regenerative braking in metro systems is to modify the driving strategy of each train in order to obtain an optimal energy-efficient timetable. Different from the forgoing energy-storage methods, a timetable optimization method does not incur any additional capital costs. It rearranges the departure and arrival times of the rolling stock so that the energy returned by the braking trains can be simultaneously consumed by those accelerating trains. This technology has been studied by many researchers. For example, Chen [33] optimized the timetable to reduce the maximum traction power. Nasri [34] got an optimal timetable for the test system and analyzed the effect of headway and reserve time. Albrecht [35] used running time modification instead of dwell time modification to reduce the power peak and energy consumption. Fournier [36] introduced a hybrid genetic/linear programming algorithm to reduce the energy consumption. Bocharnikov [37] set a weighted combination of energy consumption and journey time requirements as an objective function and changed the rates of train acceleration, braking and coasting to get an optimal driving strategy. Kim [38] developed a mixed integer programming model to 
minimize the maximum traction energy that occurs when the trains are running simultaneously. Peña-Alcaraz [39] maximized the use of regenerative-braking energy based on a power flow model of the electrical network and applied the scheduling strategy on Line Three of the Madrid underground system. A research group from Beijing Jiao Tong University has also contributed a lot to this issue in recent years. Yang [40] proposed a timetable optimization model to increase the utilization of regenerative energy and to shorten the waiting time of the passengers at the same time with a two-objective integer programming model. Li [41] combined the timetable optimization method and speed profile optimization method to achieve a better net energy consumption performance. $\mathrm{Su}$ [42] proposed a mathematical model to maximize the utilization of recovery energy. Then he also integrated the fleet size and cycle time decision, distribution of cycle time and driving strategy optimization to find a globally optimal schedule [43].

However, all the above researchers only considered how to generate an optimal timetable. None of them considered the solution on how to adapt the established timetable under disturbances, which is a very common situation, to a certain metro train. For example the doors of the train have to be reclosed if the train is too crowded or something got stuck in the doors. Although this kind of disturbance may only contribute to some short delay of the schedule, it may indeed change the subtle balance of the optimal timetable significantly, which will lead to extra energy costs. In this paper, a novel algorithm named Compensational Driving Strategy Algorithm (CDSA), which is motivated by the real demand of Shanghai Metro Line One, is developed especially for solving the disturbance problem.

This paper is arranged as follows: in Section 2, a new integrated Energy-efficient Operation Methodology (EOM) of metro systems is proposed. First, the timetable of the metro system is optimized to make full use of the regenerative braking energy. Then, the driving strategy of the metro train is changed automatically according to the CDSA under disturbance. In Section 3, a real case of Shanghai Metro Line One (SMLO) is studied and experiments were done to validate the correctness and effectiveness of the EOM energy-savings. A six-station, four-train and bidirectional pilot system, from Xujiahui Station to People's Square Station, is established in Simulink. Finally, the EOM is applied to the pilot system and the energy consumption is compared among different situations. The results show that $5.12 \%$ of the total energy is saved when there is no disturbance. Under disturbance conditions, $81.98 \%$ more energy on average can be saved with CDSA.

\section{The Energy-Efficient Operation Methodology (EOM)}

\subsection{Timetable Optimization}

Timetable optimization is a method that does not incur in additional costs when regenerative braking energy is used, compared with other energy-storage methods such as using supercapacitors or flywheels. The main idea is to synchronize the dwell time of each train at every station and make the braking and acceleration happen simultaneously so that the regenerative braking energy can be used to the greatest extent, which is illustrated in Figure 1.

Figure 1 shows the power consumption of two metro trains in the same metro system. The positive value of the power means the train is consuming energy (accelerating) while the negative implies the train is feeding regenerative energy back to the system (braking). If one train is braking while some 
other trains are accelerating at the same time, part of the regenerative energy can be used by the accelerating trains. The saved energy is highlighted in red in the figure. Otherwise, this part of the energy will be wasted on some resistors and transformed into heat. In the upper diagram it can be seen that only a little bit of the regenerative energy is used because the dwell time of the 2 nd train is not optimized. However, if more dwell time is added to the 2nd train, illustrated on the lower diagram, the red part increases dramatically, which means that more energy is saved in the second situation.

Figure 1. Change dwell time to use regenerative energy.

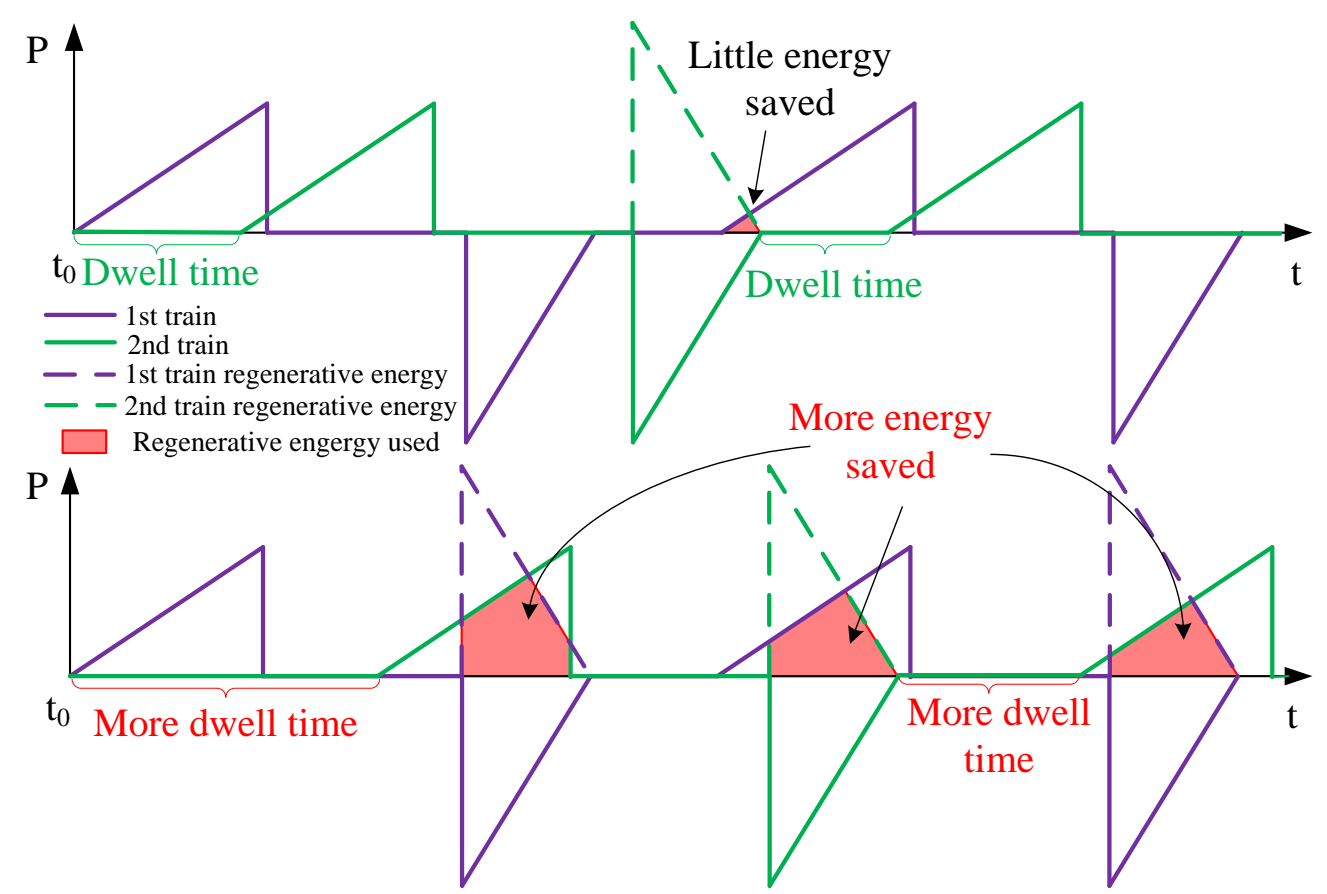

To get an optimal timetable, we set the dwell time of the train as decision variables. Suppose there are $N$ periods of dwell time that can be changed for each train and there are $M$ trains in the whole system, so there are $K$ variables in total:

$$
K=N \cdot M
$$

In real situations, the dwell time can be modeled as two types: the fixed dwell time and the flexible dwell time. The former one, which is the necessary time for passengers to board the train, is fixed as a constant. The latter one, which has an upper bound of $x_{\max }$, is set as the variables $x_{i}(i=1,2, \ldots, K)$. So the optimization problem can be formulated as follows:

$$
\begin{aligned}
\min E & =\sum_{j=1}^{Q} \int_{0}^{t_{f}} U_{j}\left(t, x_{1}, x_{2}, \ldots, x_{K}\right) \cdot I_{j}\left(t, x_{1}, x_{2}, \ldots, x_{K}\right) d t \\
\text { s.t. } 0 & \leq x_{i} \leq x_{\max } \quad i=1,2, \ldots, \mathrm{K} \\
& x_{i} \text { is integer } \quad i=1,2, \ldots, \mathrm{K}
\end{aligned}
$$

where $E$ represents the total energy consumption of the system, $Q$ is the number of substations of power supply for the metro system, $t_{\mathrm{f}}$ is the total travelling time of the system, and $U_{j}$ and $I_{j}$ are the Direct Current (DC) voltage and current of the $j$ th substation, respectively. 
The optimization problem of Equation (2) is an Integer Programming Problem (IPP). In this paper, it is solved by the Mixed Integer-Laplace Crossover Power Mutation (MI-LXPM) genetic algorithm that was proposed in [44]. It is a real coded genetic algorithm, which means the decision variables are encoded with real numbers instead of binary code. The whole algorithm is made up of Laplace crossover, power mutation, tournament selection, constraint handling techniques, and truncation procedure for integer restrictions.

\subsection{Compensational Driving Strategy Algorithm}

With the optimal timetable, a certain percentage of the total energy consumption can be reduced if all the metro trains strictly stick to it. However, this is not necessarily the case in real situations. When the trains are in service, there are a variety of disturbances that will keep the train off the established timetable, such as doors that cannot open or reopen/reclose for safety purposes. Normally this kind of disturbance does not last very long and can be fixed automatically. Nevertheless, since the energy-efficient timetable is arranged for the optimized simultaneous use of accelerating and braking among all the metro trains, such a time delay may cause a suboptimal use of the regenerative energy and influence the later operation of the disturbed train. Consequently, a little amount of time delay would significantly break the balance of the use of regenerative energy and reduce the energy-saving effect. In this section, a novel algorithm named Compensational Driving Strategy Algorithm (CDSA) is introduced to save the additional energy when disturbances happen.

First, the driving strategy of a single metro train has to been determined. By the application of Pontryagin's Maximum Principle, Horn [45] has proven that the optimal driving scheme consists of maximum five ordered phases:

1 Driving with maximal acceleration;

2 Traveling with constant speed (cruising);

3 Coasting;

4 Braking to target with maximal deceleration;

5 Waiting for passengers to board the train (dwelling).

Moreover, as for the specific metro system such as SMLO, only four phases of acceleration, coasting, braking and dwelling are needed in normal operation conditions because the metro system always has a relatively short station spacing (normally 1 to $2 \mathrm{~km}$ ) $[3,42,46]$. Note that this driving strategy modeling is a simplified model that is based on the real case of SMLO. Whether there is a cruising process or not will depend on the maximum speed and the station spacing of the line. If this maximum speed is not high enough or the station spacing is too long, it is necessary to travel at a constant speed to reach the next station or even re-motor the train in the middle of the journey. The schematic diagram of the driving strategy is shown in Figure 2.

In Figure $2, t_{1, n}, t_{2, n}, t_{3, n}$ and $t_{4, n}$ represent the durations of acceleration, coasting, braking, and dwelling between the $n$th and $(n+1)$ th stations, respectively. $a_{1, n}, a_{2, n}$, and $a_{3, n}$ are the accelerations of accelerating, coasting, and braking between the $n$th and $(n+1)$ th stations, respectively. $v_{1, n}$ and $v_{2, n}$ are the instant speeds at the end of the acceleration and the coasting between the $n$th and $(n+1)$ th stations, respectively. In order to maintain the safety, the speed of the train at each stage cannot exceed the limit 
set by the red line. The blue line represents a typical Automatic Train Operation (ATO) system, whose function is to drive the train automatically according to a set of pre-programmed speed profile.

Figure 2. The schematic diagram of the driving strategy.

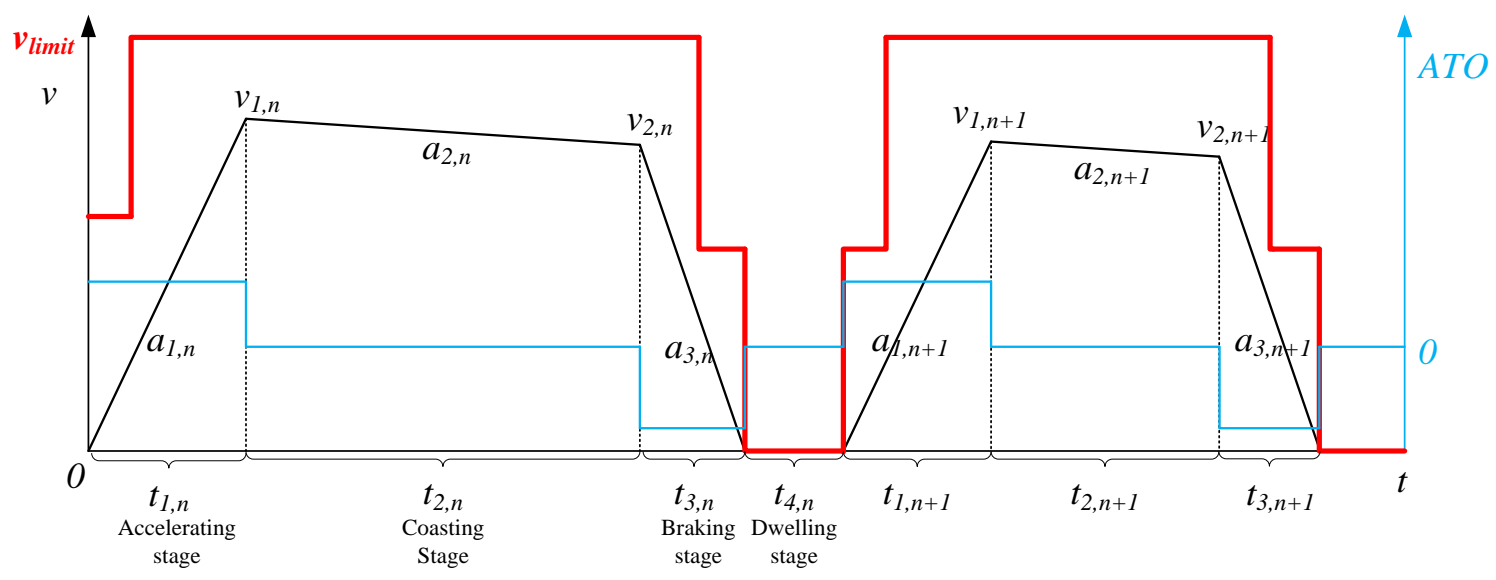

As shown in Figure 2, the proposed driving strategy for a single train seems to be diverse. However, not all the variables can be changed for a certain metro train. In fact, $a_{1, n}$ and $a_{3, n}$ are always set to be a constant value in real situations, which is shown by the experiment in Section 3. The variable $a_{2, n}$, however, has a tricky value. In fact, $a_{2, n}$ is determined by the running resistance $F_{\mathrm{r}}$, which has the following equation:

$$
F_{\mathrm{r}}=A+B v+C v^{2}
$$

Equation (3) is called the Davis equation [47], where $A, B$, and $C$ are coefficients specific to certain rolling stock. Usually $B$ and $C$ are much smaller than $A$, so we can also treat $a_{2, n}$ as a constant value of $a_{2}$ for simplicity if the gradient is assumed to be constant (this also can be proved in the real case in Section 3). So, the driving process can be treated as three segments of uniformly accelerated motion. Thus, as long as $v_{1, n}$ and $t_{2, n}$ are determined, the travelling distance can be calculated, which means the distance $L_{n}$ is the function of $v_{1, n}$ and $t_{2, n}$. According to the basic formulation of dynamics, the relationship can be derived as follows:

$$
\begin{aligned}
& L_{n}=\int_{t_{\text {stat }, n}}^{t_{\text {satar }, n}+t_{1, n}} a_{1, n} t d t+\int_{t_{\text {stat }, n}+t_{1, n}}^{t_{\text {start }, n}+t_{1, n}+t_{2, n}}\left[a_{2, n} \cdot\left(t-t_{\text {start }, n}-t_{1, \mathrm{n}}\right)+v_{1, n}\right] d t \\
& +\int_{t_{\text {satr }, n}+t_{1, n}+t_{2, n}}^{t_{\text {tart } n}+t_{1, n}+t_{2, n}+t_{3, n}}\left[a_{3, n} \cdot\left(t-t_{\text {start }, n}-t_{1, \mathrm{n}}-t_{2, \mathrm{n}}\right)+v_{2, n}\right] d t
\end{aligned}
$$

where $t_{\text {start }, n}$ is the start time of the train leaving the $n$th station and can be calculated as:

$$
t_{\text {start }, n}=\sum_{i=1}^{n-1} t_{1, i}+t_{2, i}+t_{3, i}+t_{4, i}
$$

In addition, we have:

$$
\begin{gathered}
v_{1, n}=a_{1} t_{1, n} \\
v_{2, n}=v_{1, n}+a_{2} t_{2, n}
\end{gathered}
$$


Then substituting $v_{1, n}$ and $v_{2, n}$ in Equation (4) from Equations (6) and (7), and treating $v_{1, n}$ and $t_{2, n}$ as variables, we get Equation (8):

$$
L_{n}=\frac{k_{1}}{2 a_{1}} v_{1, n}^{2}+\frac{a_{2} k_{2}}{2} t_{2, n}^{2}+k_{2} v_{1, n} t_{2, n}
$$

where:

$$
\begin{aligned}
& k_{1}=\frac{a_{3}-a_{1}}{a_{3}} \\
& k_{2}=\frac{a_{3}-a_{2}}{a_{3}}
\end{aligned}
$$

Let's say that a disturbance causes a time delay at the $n$th station. For convenience, all the variables used in CDSA are symbolized the same as before except that there is a prime on each variable, e.g., the instant speed of $v_{1, n}$ is symbolized as $v_{1, n}$ in CDSA. The very instinct idea of CDSA is to drive the train faster to make up the delay, which is shown in Figure 3.

Figure 3. Drive faster to make up the delay.

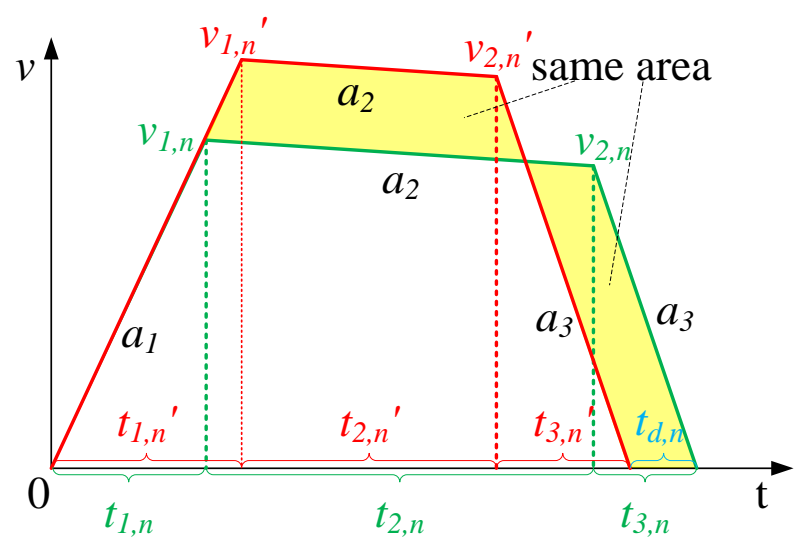

Figure 3 shows two driving strategies between the $n$th and $(n+1)$ th stations. The first strategy, the original one, is depicted as the green line. The second strategy, which is shown by the red line, has a greater maximal speed and consequently takes less travelling time. Thus, the time difference between the two strategies can be used to make up the delay. However, according to Equation (4), the yellow area covered by the two driving strategies should be the same because the travelling distances of the two strategies are the same.

The next question should be foreseen and determined is how fast the train should be driven and how much time delay can be compensated at most. In fact, there has to be a $t_{\mathrm{cmax}, n}$ that can compensate at most for the previous delay. Obviously, it is the case that the metro train can be driven at its maximal limited speed, so given the time delay of the previous station as $t_{\mathrm{d}, n-1}$, and this time delay is to be compensated at the next station, we have:

$$
v_{1, n}{ }^{\prime}=v_{\max }
$$

Solving Equation (8) for $t_{2, n}$, we have: 


$$
t_{2, n}=\frac{-k_{2} v_{1, n}+\sqrt{\Delta\left(v_{1, n}\right)}}{a_{2} k_{2}}
$$

where:

$$
\Delta\left(v_{1, n}\right)=\left(k_{2} v_{1, n}\right)^{2}-2 a_{2} k_{2}\left(\frac{k_{1} v_{1, n}^{2}}{2 a_{1}}-L_{n}\right)
$$

In addition, according to Figure 2, we have:

$$
t_{n}=t_{1, n}+t_{2, n}+t_{3, n}=\frac{v_{1, n}}{a_{1}}-\frac{v_{1, n}}{a_{3}}+\frac{a_{3}-a_{2}}{a_{3}} t_{2, n}
$$

where $t_{n}$ is the total running time between the $n$th and $(n+1)$ th station. From Equations (11), (12) and (14), we can get the minimum travelling time allowed as follows:

$$
t_{\min , n}{ }^{\prime}=\frac{v_{\max }}{a_{1}}-\frac{v_{\max }}{a_{3}}+\left(\frac{a_{3}-a_{2}}{a_{3}}\right)\left(\frac{-k_{2} v_{\max }+\sqrt{\Delta\left(v_{\max }\right)}}{a_{2} k_{2}}\right)
$$

Then the maximal compensable time delay is:

$$
t_{\mathrm{cmax}, \mathrm{n}}=t_{n}-t_{\text {min,n }}{ }^{\prime}
$$

Note that if $t_{\mathrm{d}, n-1}>t_{\mathrm{cmax}, n}$, it is impossible to compensate the time delay within only one following station. The train should be driven at the maximal speed, leaving the uncompensated part of the delay as the new time delay between the $n$th and $(n+1)$ th stations and then try to compensate it in addition to the real possible time delay of this segment in the next period of travelling. Thus, the system can return to the original energy-saving status within a couple of stations. The mechanism of CDSA is shown in Figure 4.

Figure 4. The mechanism of CDSA (Compensational Driving Strategy Algorithm).

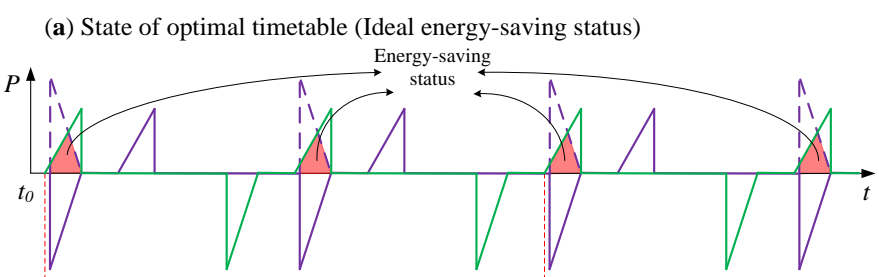

(b) Situation of disturbance (Delay eliminates the use of braking energy).

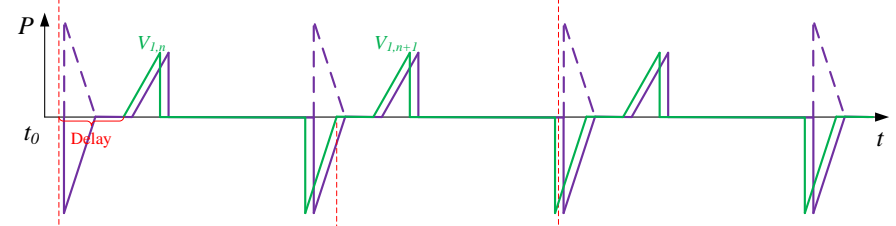

(c) Process of applying CDSA (CDSA returns the system to energy-saving status).

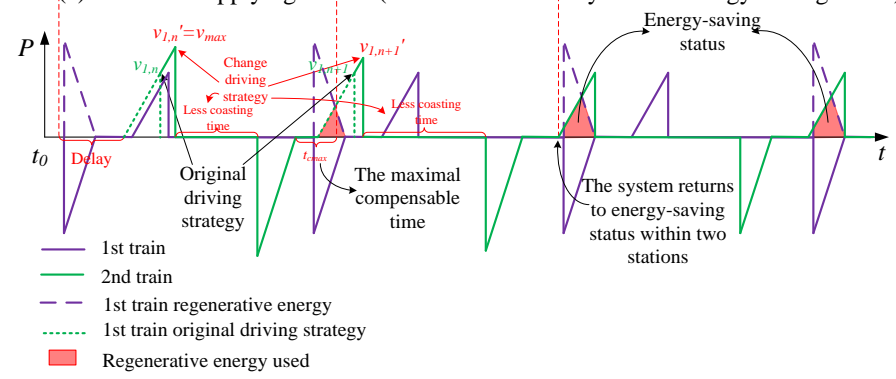


Figure 4 illustrates the power consumption of two trains with compensation of time delay by CDSA. Figure 4a indicates the status where the metro system sticks to the optimal timetable, which is the ideal energy-saving status. It can be seen that energy is saved due to timetable optimization. Figure $4 \mathrm{~b}$ shows the time delay caused by an unexpected disturbance. In this case a small amount of time delay eliminates the use of regenerative energy. Figure $4 \mathrm{c}$ represents the process of applying CDSA. When the delay happens, CDSA immediately takes effect and changes the speed of the train after leaving the $n$th station, which is indicated by the green line. In the first segment, $v_{1, n}$ of the second train is set to be $v_{\text {max }}$. In this way the travelling time between the $n$th station and the $(n+1)$ th station is saved at the most extent, which is used to compensate for the time delay. In the next segment, same thing happens except that $v_{1, n+1}$ is set to be a certain value of $v_{1, n+1}$ instead of $v_{\text {max }}$ according to CDSA. By the end of the $(n+1)$ th station, the system is returned to energy-saving status.

When the time delay at the previous station $t_{\mathrm{d}, n-1}$ is less than $t_{\mathrm{cmax}, n}$, a certain value of $v_{1, n}$ ' should be determined so that the time delay can be exactly compensated at the next stop. In this case, we have:

$$
t_{n}{ }^{\prime}=t_{n}-t_{\mathrm{d}, n-1}
$$

According to Equations (14) and (17), $t_{2, n}$ ' can be determined as follows:

$$
t_{2, n}{ }^{\prime}=p\left(v_{1, n}-v_{1, n}{ }^{\prime}\right)+q
$$

where $p$ and $q$ are the coefficients defined as follows:

$$
\begin{gathered}
p=\frac{a_{3}-a_{1}}{a_{1}\left(a_{3}-a_{2}\right)} \\
q=t_{2, n}-\frac{a_{3}}{a_{3}-a_{2}} t_{d, n-1}
\end{gathered}
$$

Substituting Equation (18) into Equation (8), we have:

$$
A\left(v_{1, n}\right)^{2}+B\left(v_{1, n}{ }^{\prime}\right)+C=0
$$

where:

$$
\begin{gathered}
A=\frac{k_{1}}{2 a_{1}}+\frac{a_{2} k_{2}}{2} p^{2}-k_{2} p \\
B=\left(k_{2}-a_{2} k_{2} p\right)\left(p v_{1, n}+q\right) \\
C=\frac{a_{2} k_{2}\left(p v_{1, n}+q\right)^{2}}{2}-L_{n}
\end{gathered}
$$

So we can determine $v_{1, n^{\prime}}$ as:

$$
v_{1, n}{ }^{\prime}=\frac{-B+\sqrt{B^{2}-4 A C}}{2 A}
$$

In conclusion, the whole algorithm is implemented according to the flowchart shown in Figure 5. 
Figure 5. The flowchart of CDSA.

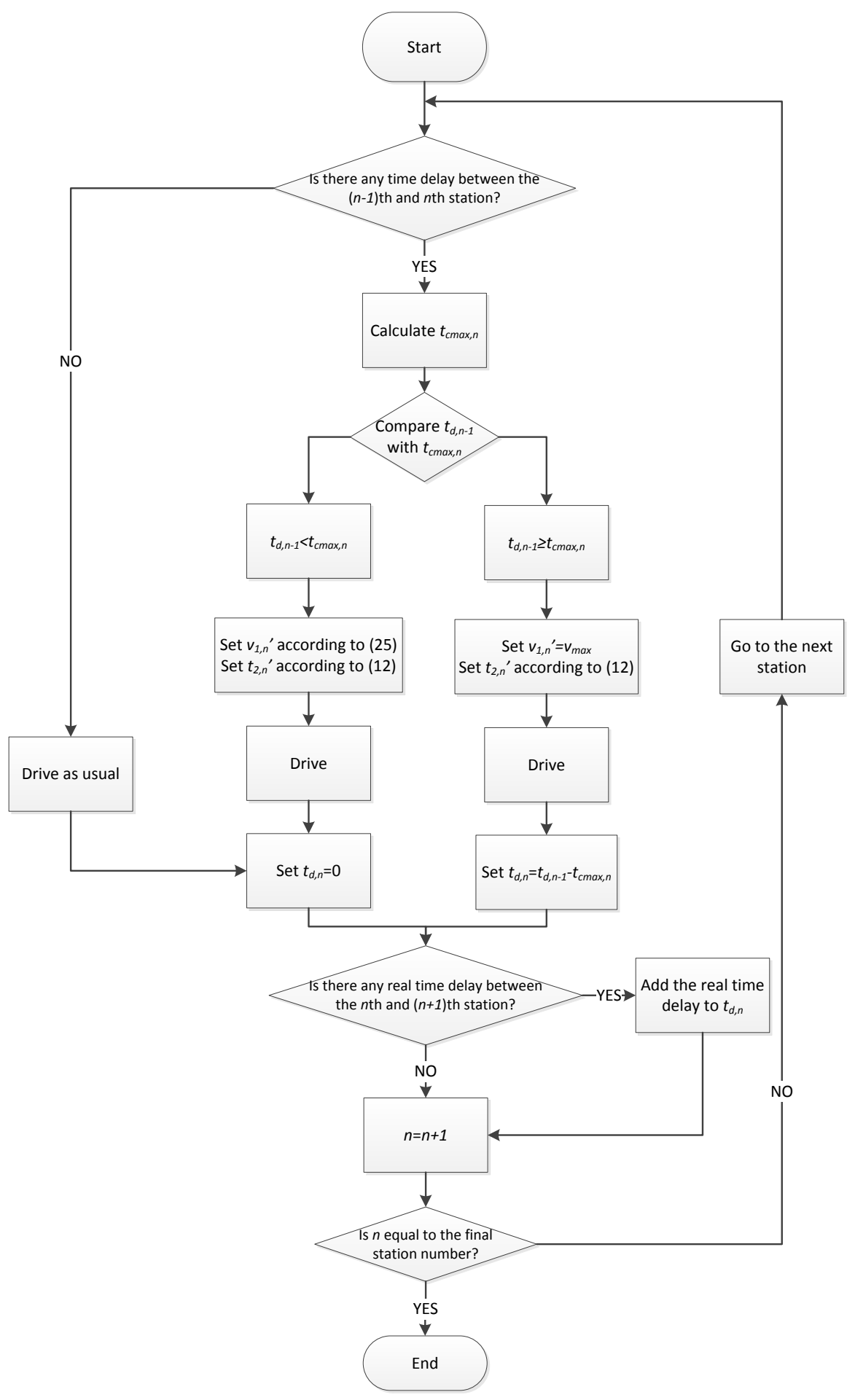

\section{Case Study: Shanghai Metro Line One}

To validate the correctness and evaluate the energy-saving effects of EOM, experiments were done on a traction box of a metro car in SMLO. Models were established in Simulink. All the data was acquired from Shanghai Shentong Metro Group Co., Ltd. 


\subsection{Experiment Data and Parameters}

Data measurement circuits were set up to acquire the online data from the traction part of a moving train. The diagram of the circuit is shown in Figure 6. The HIOKI (Nagano, Japan) 8860-50 data logger, which has 16 channels of analog inputs, up to $1 \mathrm{MS} / \mathrm{s}$ sampling rate, was used to record the pantograph's DC supply voltage \& current, breaking chopper current, and the train's speed.

Figure 6. Schematic diagram of the electrical data measurement.

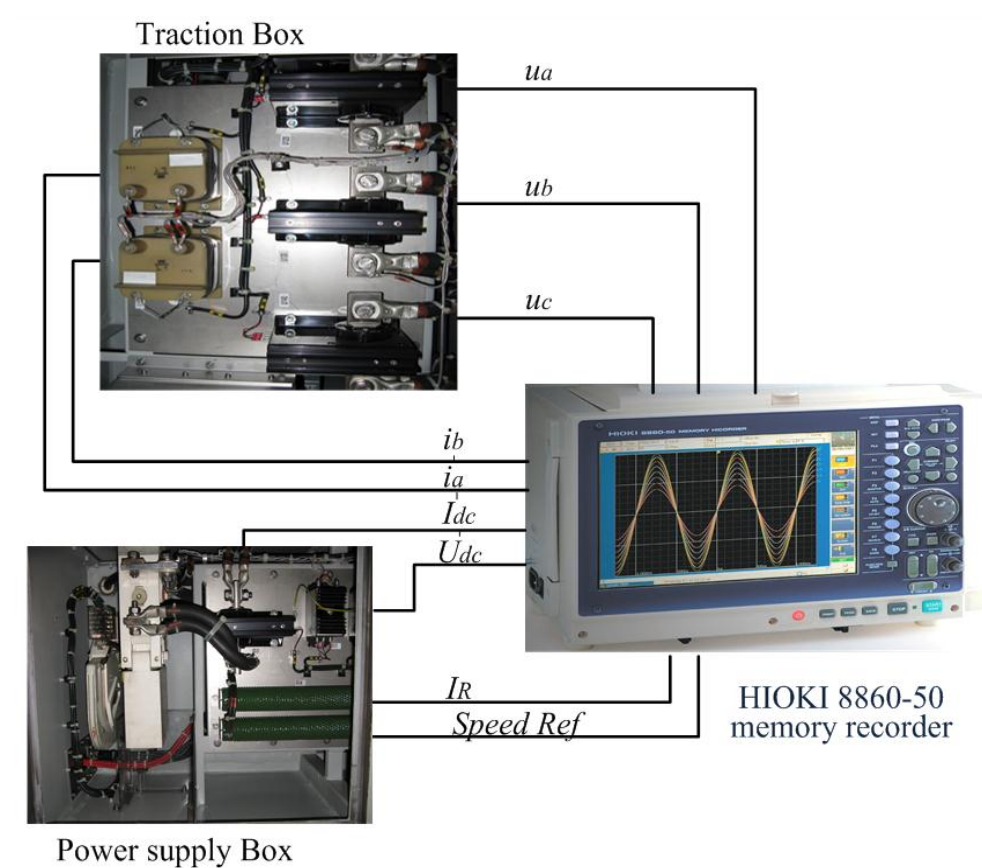

Some issues should be noted for the experiment:

1 The experiment was done on a separate power supply system designed especially for the test and maintenance, so the supply capacity is limited.

2 There were no other trains in the same supply network.

3 During the experiment, the test metro train was unloaded. That means the mass of the whole test metro train is just its own mass, which is 296 tons.

4 Most of the auxiliary electric devices, like air-conditioners, were switched off during the experiment.

5 The metro train is composed of six cars. All the measurements were taken from one of the cars.

Figure 7 shows the experiment data of the test metro car. Figure 7a records the speed profile of the test train. It shows three periods of movement. From 3 to $23 \mathrm{~s}$, the controller gave the full output to accelerate the train from 0 to $60 \mathrm{~km} / \mathrm{h}$. Then the traction motors were switched off for $7 \mathrm{~s}$. The train started braking at $30 \mathrm{~s}$. Figure 7b,c show the DC bus voltage and current of the test car, respectively. From Figure $7 \mathrm{a}$ it can be seen that the modeling of the driving strategy proposed in this paper is true and has already been applied on the real metro system. It could also be seen that when the train is accelerating, the voltage of the DC supply network was decreasing and the current demand of the train was growing fast because the train was in the process of changing from electric energy to kinetic energy. In addition, we can approximate the voltage and current as linear functions of time according 
to the diagrams. In the coasting period, the current demand decreased to zero because the power was switched off. The train speed dropped a little for the sake of extremely low resistance. In the braking process, the train started to feed the regenerative energy back. However, the regenerative braking was an effective method to save energy only when it is simultaneously used by other metro trains. If not, it would otherwise raise the voltage of the supply network, which is not permitted. Thus, a braking chopper was then used to limit the DC bus voltage by switching the braking energy to a resistor where the braking energy was converted to heat. The breaking chopper would take effect when the DC line voltage exceeds $1800 \mathrm{~V}$ in SMLO. Figure 7d shows the current of the braking chopper.

Figure 7. Experiment data of the test metro car.

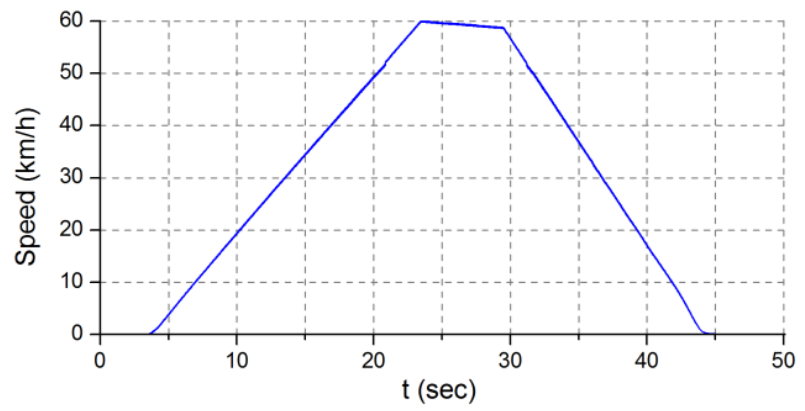

(a) Speed profile

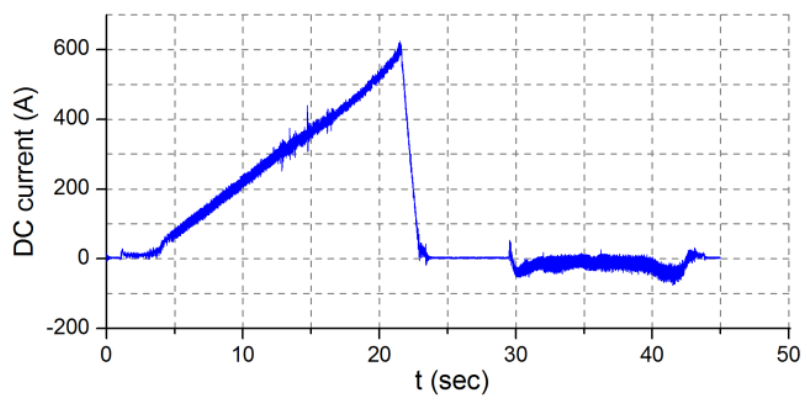

(c) DC bus current

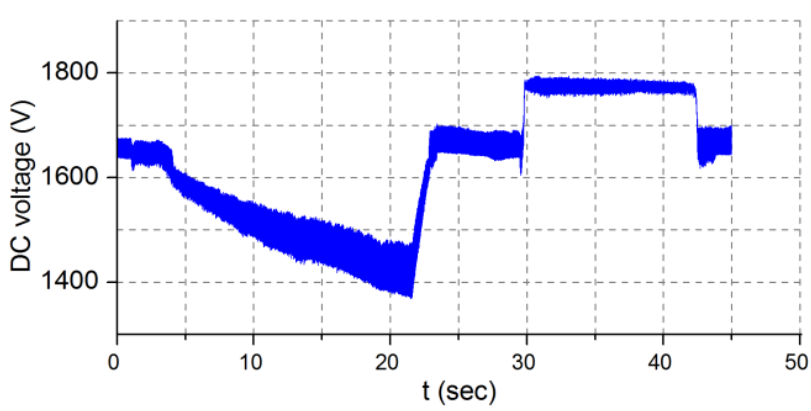

(b) DC bus voltage

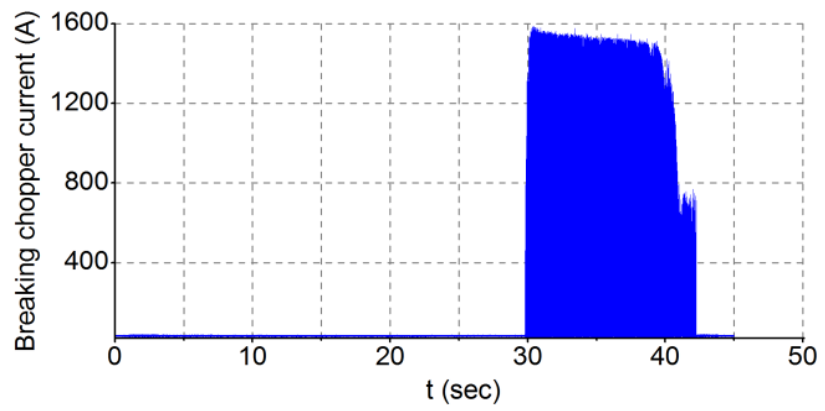

(d) Breaking chopper current

From these diagrams, we can easily derive the power of different part of energy consumption by multiplying the corresponding voltages and currents. Note that the braking chopper power was not continuous because the braking resistor was switched on discretely. It is denser in the forepart and sparser in the rear.

This is because that at the beginning of braking process, the velocity of the train is greater and thus more kinetic energy is turned into heat. If we integrate the braking chopper energy separately and add the feedback energy, we can get the absorbed power and the regenerative power of one metro car as shown in Figure 8. Recall that in Section 2, we analyzed and derived EOM based on the modeling of the power diagram with two triangles, which means linearity. Figure 8 validates the use of this power network model of metro systems. 
Figure 8. The experiment power diagram of one metro car.

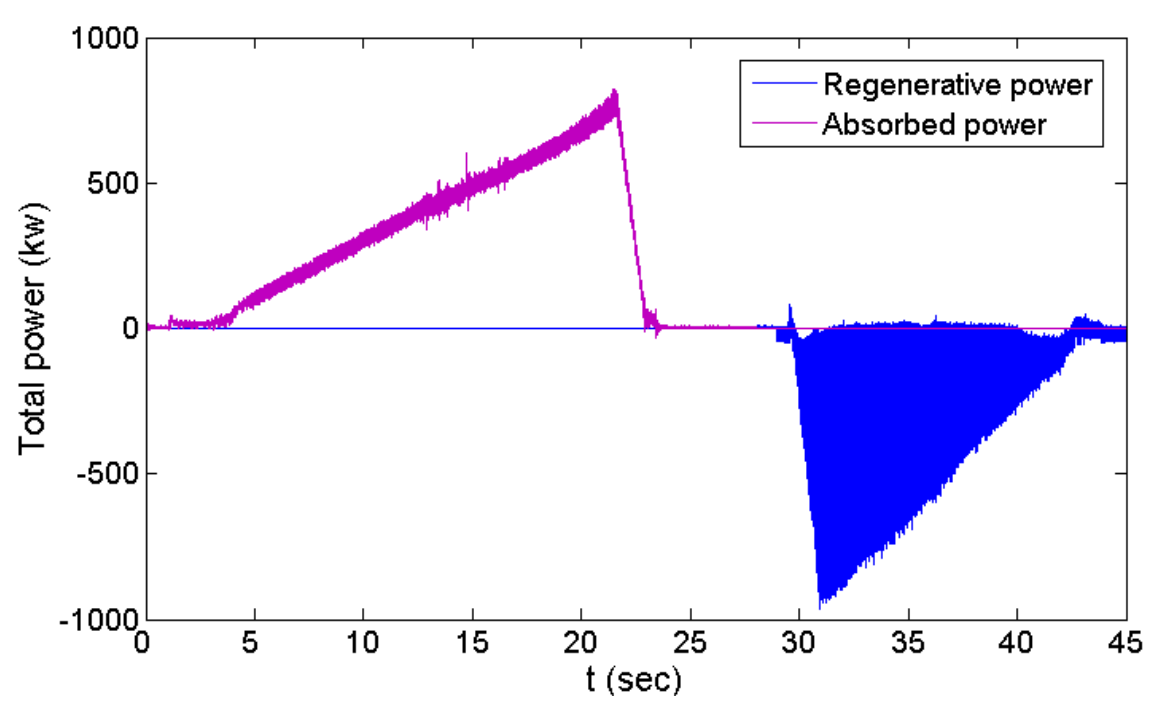

\subsection{Modeling of the Pilot Metro System}

SMLO is one of the most important and busiest transportation systems of the city. It has 28 stations with a total distance of $37 \mathrm{~km}$. For time-saving purpose, we only simulated the system with the most important segment, which contains six stations. The information of the pilot system is listed in Table 1.

Table 1. The information of the pilot system.

\begin{tabular}{ccccc}
\hline Segment No. & Starting station & Stopping station & Distance $(\mathbf{m})$ & $\boldsymbol{v}_{\mathbf{1 , n}}(\mathbf{k m} / \mathbf{h})$ \\
\hline 1 & Xujiahui & Hengshan Road & 1473 & 57.7 \\
2 & Hengshan Road & Changshu Road & 1156 & 51.1 \\
3 & Changshu Road & South Shanxi Road & 939 & 51.3 \\
4 & South Shanxi Road & South Huangpi Road & 1407 & 57.4 \\
5 & South Huangpi Road & People's Square & 1198 & 53.4 \\
\hline
\end{tabular}

In the simulation, we number the six stations in sequence from 1 to 6 . Each metro train departs at the 1st station and travels in sequence to the 6th station, which is called forward direction. Then, a turning of $60 \mathrm{~s}$ in duration occurs at the 6th station. After that, each train drives from the 6th station back to the 1st station, which is called backward direction. In the backward direction, the geographically $n$th station is defined as the $(12-n)$ th station in consistency with the forward direction. The segment between the $n$th and $(n+1)$ th station is defined as the $n$th segment. For simplicity, we modeled four trains in the system. Two of each depart from both ends of the track and turn around at the other end. The two trains have a headway time of $120 \mathrm{~s}$. The schematic diagram is shown in Figure 9. 
Figure 9. The schematic diagram of the pilot system.

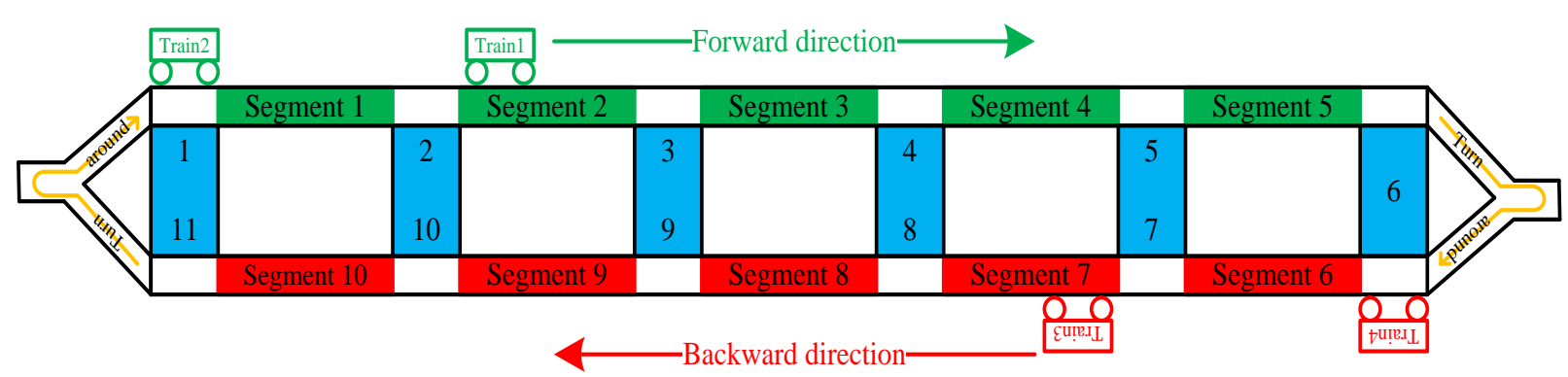

The train line of the six stations is powered by two substations at both ends of the system. According to reference [48], we model each train as a current source. In addition, from Figure 8, the DC current should have the same shape (linear) as the power because the DC voltage is also linear. This can easily be shown according to the acceleration process of Figure $7 b-c$ and Figure 8 . The equivalent circuit of the system is shown in Figure 10a.

Figure 10. Circuit model of the metro system.

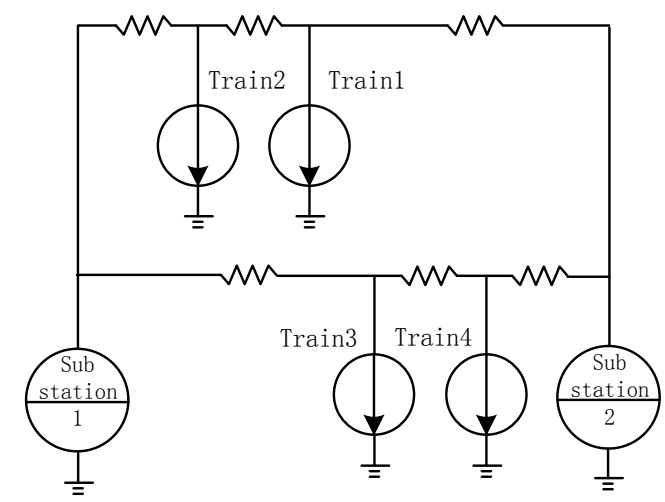

(a) The equivalent circuit

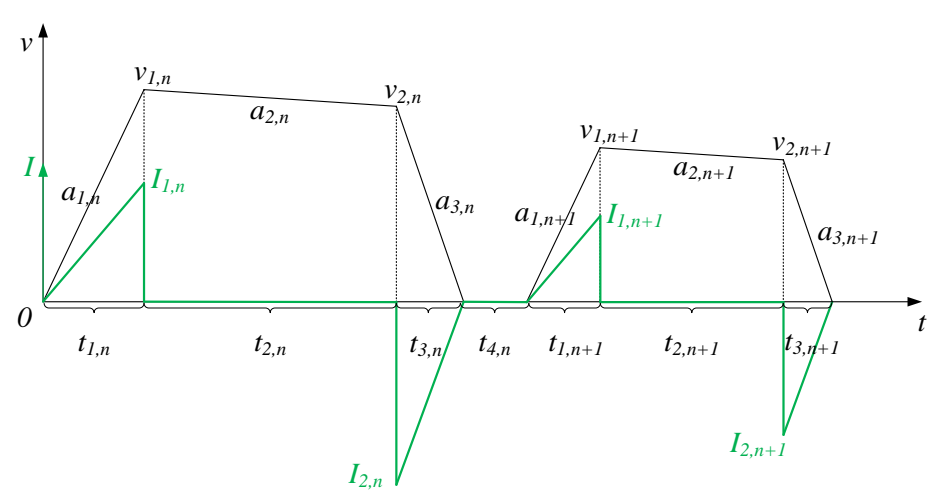

(b) The correspondence of the speed and current

The equivalent current of each train can be determined by the train's speed and the acceleration rate according to Figure 7a,c. When the train is accelerating, the current is a positive value. When the train is coasting, it does not consume any energy and the current is zero. When the train is braking, which implies feeding the energy back, the current is negative. Note that the value of the negative current is determined according to Figure 8. In this case we assume that all the regenerative energy can be utilized by other trains.

The corresponding relationship between the current and the speed of the train is shown in Figure 10b. It should be noted that the data in Figure 7c shows the current value of only one metro car. In simulation, we should multiply it by six since a real metro train consists of six such cars. The voltage of substation one and the current of all the four trains in simulation are shown in Figure 11. 
Figure 11. The voltage and current in simulation.
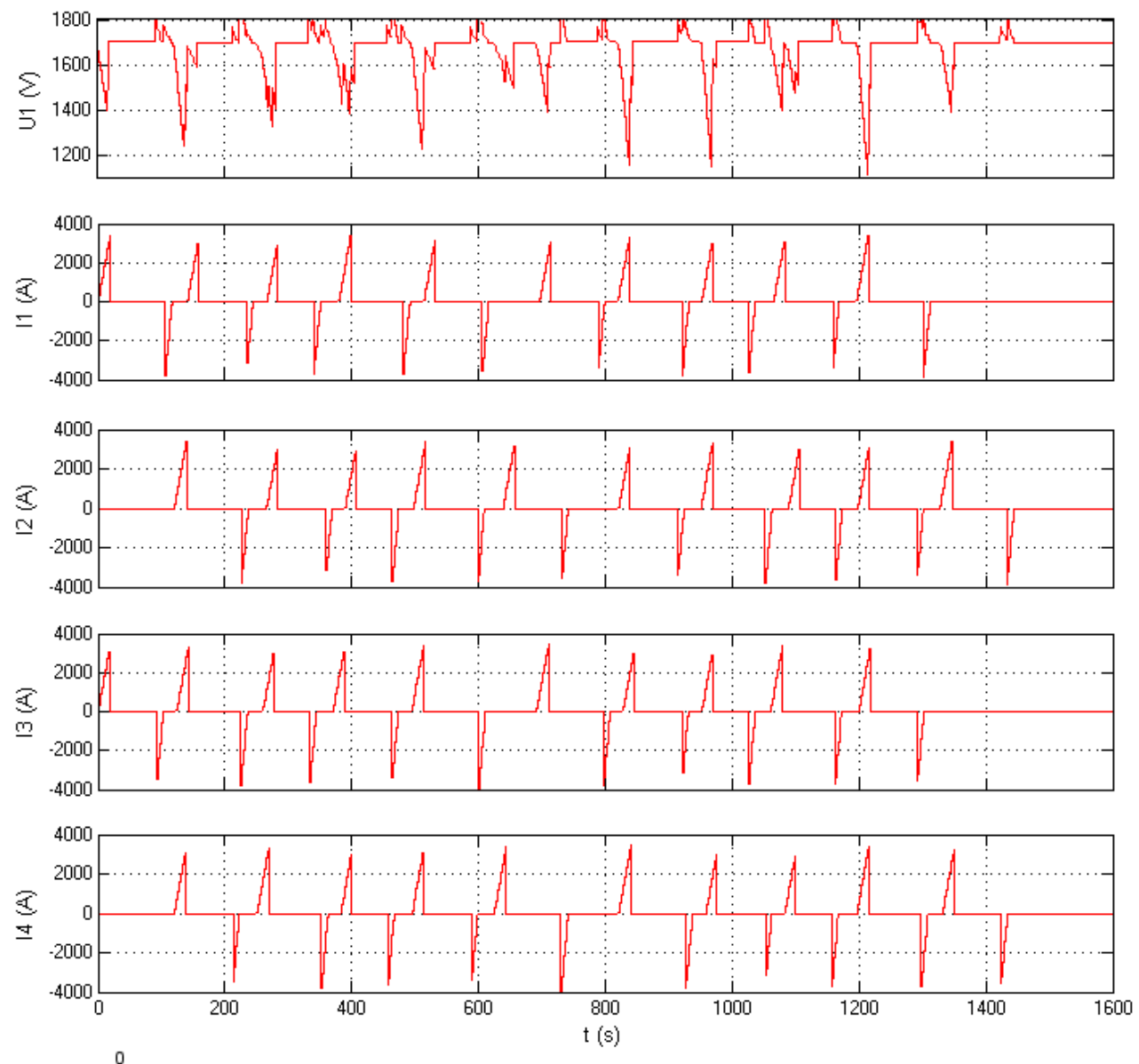

\subsection{Applying EOM to the System}

\subsubsection{Specifying the Driving Strategy}

In simulation, we got the accelerations of the accelerating and braking from Figure 7a. According to the figure, the absolute value of acceleration of coasting is very small compared with the other two. In fact, the specific Davis equation of SMLO is as follows:

$$
F_{\mathrm{r}}=16462.04+4.07 v+11.18 v^{2}
$$

From Equation (26) it can be seen that different velocity values, from 0 to $v_{\max }$, will change the running resistance by less than $30 \%$. Consequently, it will have even less influence on the train's speed if we assume a suitable value of $v$ in Equation (26), so taking $a_{2, n}$ as a constant of $a_{2}$ for simplicity in both modeling and simulation is a reasonable assumption. Note that this assumption is acceptable only in particular situation that the gradient does not vary on the track segment considered. From all above, we get the acceleration values of the pilot system as shown in Table 2.

Table 2. The acceleration values of the pilot system.

\begin{tabular}{cccc}
\hline Parameter & $\boldsymbol{a}_{\mathbf{1}}\left(\mathbf{m} / \mathbf{s}^{2}\right)$ & $\boldsymbol{a}_{\mathbf{2}}\left(\mathbf{m} / \mathbf{s}^{2}\right)$ & $\boldsymbol{a}_{3}\left(\mathbf{m} / \mathbf{s}^{2}\right)$ \\
\hline Value & 0.8333 & -0.0363 & -1.1723 \\
\hline
\end{tabular}


Also, Equation (8) will have a specific form for the pilot system, which is:

$$
L_{n}=1.0265 v_{1, n}^{2}-0.0176 t_{2, n}^{2}+0.9690 v_{1, n} t_{2, n}
$$

From Equation (27) and Table 1, the specified driving strategy for the pilot system is shown in Table 3.

Table 3. The specified driving strategy of the pilot system.

\begin{tabular}{cccccc}
\hline Segment No. & $\boldsymbol{t}_{\mathbf{1 , n} \boldsymbol{n}}(\mathbf{s})$ & $\boldsymbol{t}_{\mathbf{2}, \boldsymbol{n}}(\mathbf{s})$ & $\boldsymbol{t}_{\mathbf{3}, \boldsymbol{n}}(\mathbf{s})$ & $\boldsymbol{v}_{\mathbf{1}, \boldsymbol{n}}(\mathbf{m} / \mathbf{s})$ & $\boldsymbol{v}_{\mathbf{2}, \boldsymbol{n}}\left(\mathbf{m} / \mathbf{s}^{\mathbf{2}}\right)$ \\
\hline 1 & 19.23 & 86.31 & 11.00 & 16.03 & 12.89 \\
2 & 17.03 & 76.50 & 9.74 & 14.19 & 11.42 \\
3 & 17.10 & 57.06 & 10.39 & 14.25 & 12.18 \\
4 & 19.13 & 81.80 & 11.07 & 15.94 & 12.98 \\
5 & 17.80 & 74.42 & 10.35 & 14.83 & 12.13 \\
\hline
\end{tabular}

\subsubsection{Using TO}

According to Equation (2), we set the fixed dwell time to be $20 \mathrm{~s}$ and the flexible dwell time maximum $10 \mathrm{~s}$ in the pilot system by considering the real situation. For each train, there are eight dwell times that can be changed, that is at station $2,3,4,5,7,8,9$, and 10 . So there are 32 variables in total. The travelling time of the system, i.e., the simulation time, is set to be $1600 \mathrm{~s}$, so the specified optimization problem of Equation (2) is as follows:

$$
\begin{aligned}
\min E & =\sum_{j=1}^{2} \int_{0}^{1600} U_{j}\left(t, x_{1}, x_{2}, \ldots, x_{32}\right) \cdot I_{j}\left(t, x_{1}, x_{2}, \ldots, x_{32}\right) d t \\
\text { s.t. } & 0 \leq x_{i} \leq 10 \quad i=1,2, \ldots, 32 \\
& x_{i} \text { is integer } \quad i=1,2, \ldots, 32
\end{aligned}
$$

When MI-LXPM is used to solve Equation (28), we set the population size as 40, crossover fraction as 0.8 , and elite count as 5 . The algorithm finds the best solution in 50 generations. The results are shown in Figure 12.

Figure 12. The results of the genetic algorithm.

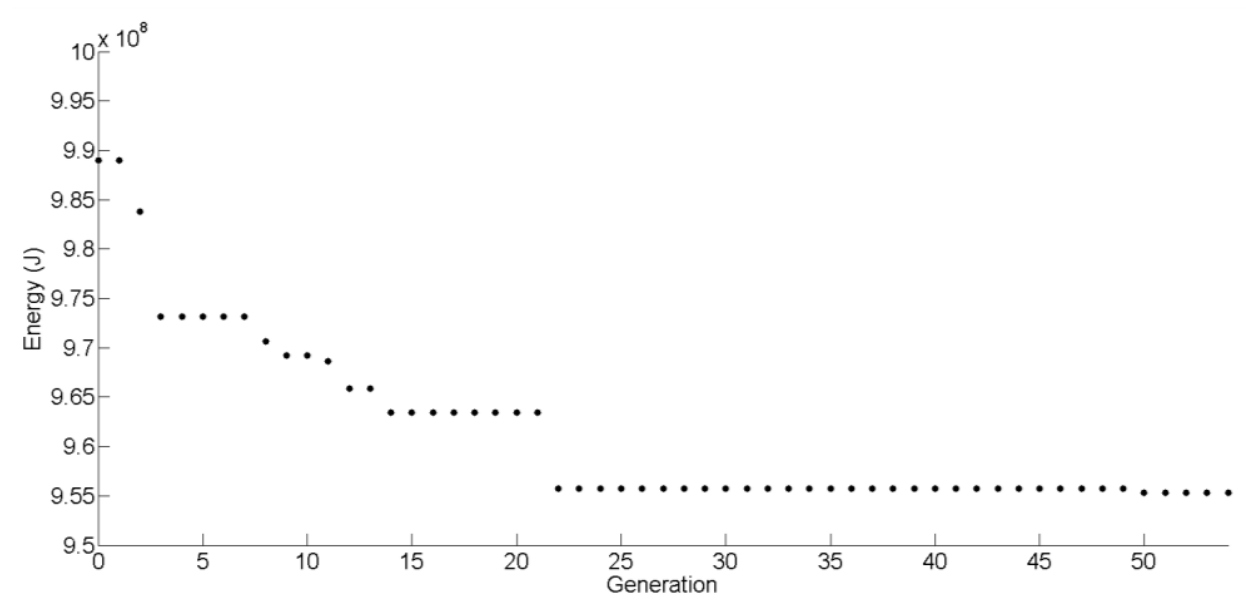

(a) The evolutionary process of the genetic algorithm 
Figure 12. Cont.

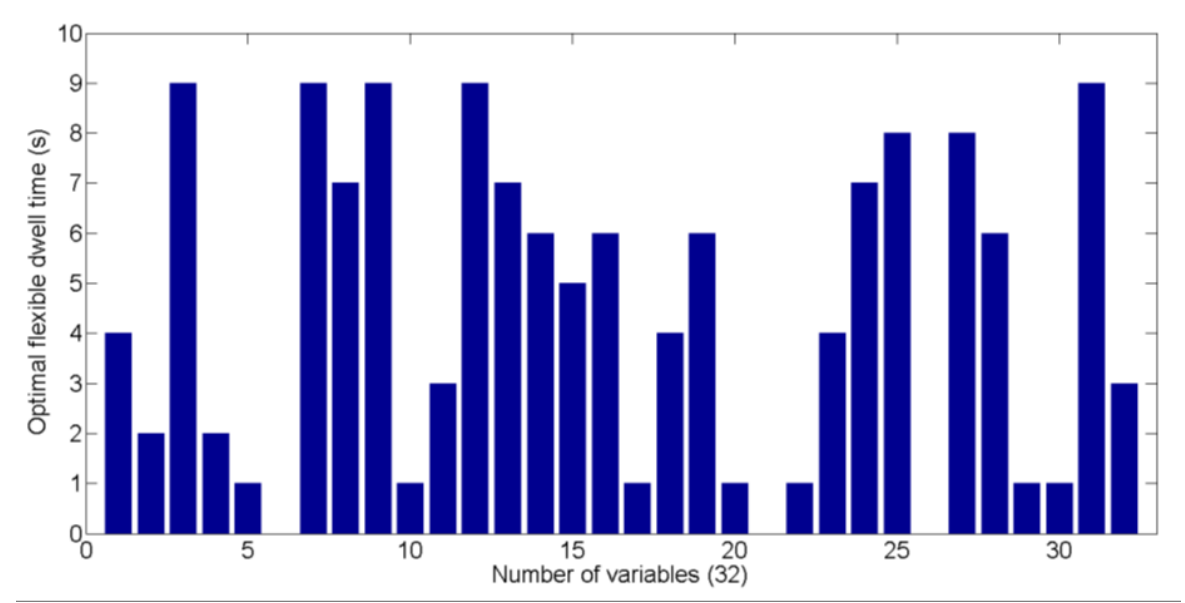

(b) The best solution of the flexible dwell time

With the best solution, we can get the optimal energy-efficient timetable of departure time of the pilot system as shown in Table 4.

\subsubsection{Applying CDSA}

Under disturbance, CDSA is applied in order to recover the system to energy-saving status. Figure 13 shows the current and the corresponding energy consumption of different situations. Suppose that a disturbance of $20 \mathrm{~s}$ occurs on the 1 st train at the dwell time of the 2 nd station. The green line shows the optimal timetable of the 1st train. The red line and the blue line show the situations with and without CDSA, respectively. At the first two stations, the train is operating at its optimal status so that everything was fine and the three lines stuck together. From the 3rd station, the three lines separated. Both the red line and the blue line were delayed 20 seconds. However, with CDSA, the red line caught up with the green line and the system returned to energy-saving status from the 4th station. The ultimate energy consumption shows clearly that CDSA can compensate for a certain amount of energy.

To get an unbiased performance of CDSA, the Monte Carlo method [49] is used. In each experiment, a disturbance that has a normal distribution with expectation of $20 \mathrm{~s}$ is applied randomly to the four trains at a random station. Then CDSA is activated automatically on the delayed train to keep it on schedule. Finally, we compare the energy-saving effects of the two situations with and without CDSA. The result is shown in the next section. Note that CDSA is designed to be applied independently on each train on the line. It is focused on whether the specific train is delayed or not and then tries to compensate it, so if several trains are delayed, CDSA will take effect automatically and independently on each delayed train, which means there will be no significant difference if several disturbances happen. On the other hand, according to the current operating mechanism of SMLO, short delays are usually not being recovered or unable to be recovered until the end of a single journey as long as they are not significant enough to cause some safety problems. This existing mechanism is simulated and compared with the CDSA introduced in this paper in the next section. 
Table 4. The optimal departure time at each station.

\begin{tabular}{|c|c|c|c|c|c|c|c|c|c|}
\hline \multicolumn{2}{|c|}{$\begin{array}{c}\text { Trains depart from } \\
\text { this end }\end{array}$} & Xujiahui & $\begin{array}{c}\text { Hengshan } \\
\text { Road } \\
\end{array}$ & $\begin{array}{c}\text { Changshu } \\
\text { Road }\end{array}$ & $\begin{array}{c}\text { South Shanxi } \\
\text { Road } \\
\end{array}$ & $\begin{array}{c}\text { South Huangpi } \\
\text { Road } \\
\end{array}$ & \multirow[t]{2}{*}{$\begin{array}{l}\text { People's } \\
\text { Square }\end{array}$} & \multicolumn{2}{|c|}{$\begin{array}{c}\text { Trains depart from } \\
\text { this end }\end{array}$} \\
\hline \multirow{2}{*}{ Train 1} & Forward & 8:00:00 & $8: 02: 21$ & $8: 04: 26$ & 8:06:19 & 8:08:33 & & & \\
\hline & Backward & $8: 23: 12$ & $8: 19: 55$ & $8: 17: 45$ & $8: 15: 52$ & $8: 13: 40$ & $8: 11: 36$ & & \\
\hline \multirow{6}{*}{ Train 2} & Forward & 8:02:00 & $8: 04: 26$ & $8: 06: 30$ & $8: 08: 17$ & $8: 10: 38$ & \multirow{2}{*}{$8: 13: 41$} & & \\
\hline & Backward & $8: 25: 24$ & $8: 22: 07$ & $8: 19: 58$ & 8:18:09 & $8: 15: 51$ & & & \\
\hline & & \multirow{2}{*}{$8: 11: 31$} & $8: 08: 14$ & $8: 06: 10$ & $8: 04: 20$ & 8:02:04 & 8:00:00 & Backward & \multirow{2}{*}{ Train 3} \\
\hline & & & $8: 13: 57$ & 8:16:02 & $8: 17: 50$ & 8:20:09 & $8: 23: 12$ & Forward & \\
\hline & & \multirow{2}{*}{ 8:13:41 } & $8: 10: 24$ & 8:08:15 & $8: 06: 23$ & $8: 04: 11$ & 8:02:00 & Backward & \multirow{2}{*}{ Train 4} \\
\hline & & & $8: 15: 58$ & $8: 18: 03$ & $8: 19: 56$ & $8: 22: 11$ & $8: 25: 14$ & Forward & \\
\hline
\end{tabular}


Figure 13. Current curves and the corresponding energy consumption curve.

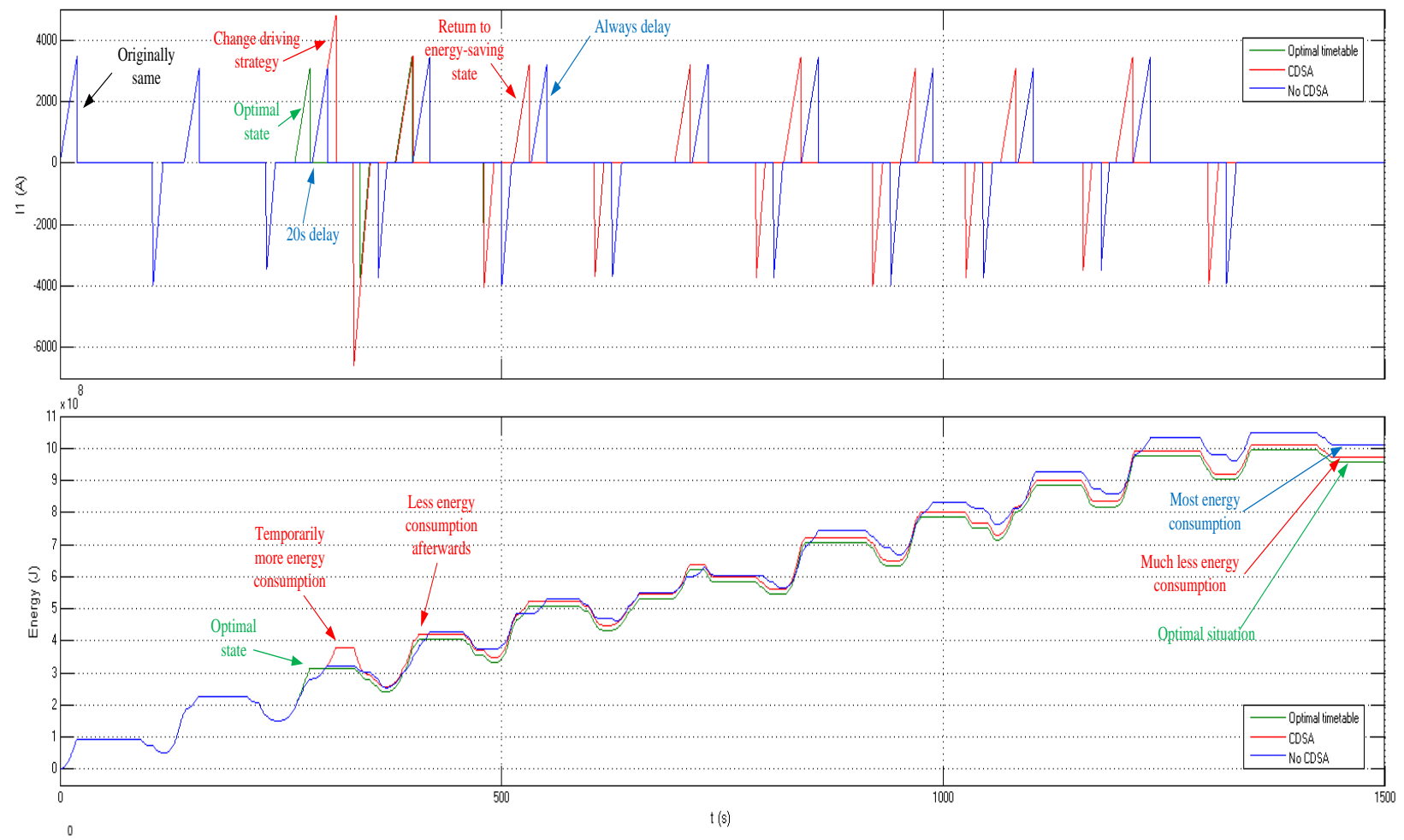

\subsection{The Energy-Saving Analysis of EOM}

The energy-saving effect is remarkable with the optimal timetable. A total number of 100 experiments were done to get an unbiased statistical result. The result is shown in Table 5.

Table 5. Average energy-saving effect of different situations.

\begin{tabular}{cccc}
\hline Different situations & $\begin{array}{c}\text { Average energy } \\
\text { consumption (MJ) }\end{array}$ & $\begin{array}{c}\text { Average energy } \\
\text { saving (MJ) }\end{array}$ & $\begin{array}{c}\text { Average energy-saving } \\
\text { percentage (\%) }\end{array}$ \\
\hline Original timetable & 1007.05 & 0 & 0 \\
Optimal timetable & 955.46 & 51.59 & 5.12 \\
Disturbance without CDSA & 984.71 & 22.34 & 2.22 \\
Disturbance with CDSA & 966.39 & 40.66 & 4.04 \\
\hline
\end{tabular}

From Table 5 it can be seen that with timetable optimization, $51.59 \mathrm{MJ}(5.12 \%)$ of energy is saved in the pilot system. When a disturbance occurs, only $22.34 \mathrm{MJ}(2.22 \%)$ of the total energy is saved on average. However, $40.66 \mathrm{MJ}$ (4.04\%) of the total energy can be saved if CDSA is applied. This shows that $81.98 \%$ more energy can be saved by using CDSA under disturbance conditions. Considering the small scale of the pilot system, the energy-saving effect is noticeable. If applied to a real metro system with much larger scale, i.e., hundreds of metro trains and stations, EOM will definitely have a much more significant result.

To get a more detailed analysis, the average energy-saving effect of each station where the disturbance happens is shown in Figure 14. It can be seen from the blue bar that the earlier the disturbance happens, the less energy would be saved if CDSA was not applied. This is because that TO 
synchronizes the accelerating and braking on a system level. The earlier the disturbance occurs, the earlier it will break the balance of the synchronization and the less energy will be saved consequently. On the other hand, from Figure 14, it can also be seen that more energy is saved with CDSA than without for earlier disturbances, which is shown by the difference of the red bar and the blue bar. For example, if the disturbance occurs at the 1 st station, nearly $5 \%$ of the total energy can be saved with CDSA (red bar) while only $1 \%$ is saved without CDSA (blue bar). The difference is about $4 \%$. If the disturbance occurs at the 8th station, nearly $5 \%$ of the total energy can be saved with CDSA. However, without CDSA, nearly $4 \%$ energy can still be saved, of which the difference is only about $1 \%$. In other words, this shows that the CDSA has a better performance for earlier disturbances.

Note that the energy-saving percentage using CDSA is less when the disturbance occurs at the 9th station. This is because that using CDSA means raising the train's travelling speed temporarily, trading for sticking to the later system-level energy-efficient timetable. Faster speed means more energy consumption. This temporarily more energy consumption can usually be overwhelmed easily by the later system-level-saved energy, which is the case of stations 1 to 8 . However, there is no more station after the 10th station. Thus, the using of CDSA caused an opposite effect at the 9th station. This phenomenon can also be seen from Figure 13. The application of CDSA caused more energy consumption temporarily at the beginning of the 3rd station. However, the eventual overall energy consumption is much less compared with the case without CDSA, so for a more realistic application of CDSA, whether it should be used or not at the end of a journey shall be considered seriously.

Figure 14. Average energy-saving effect with and without CDSA among different stations.

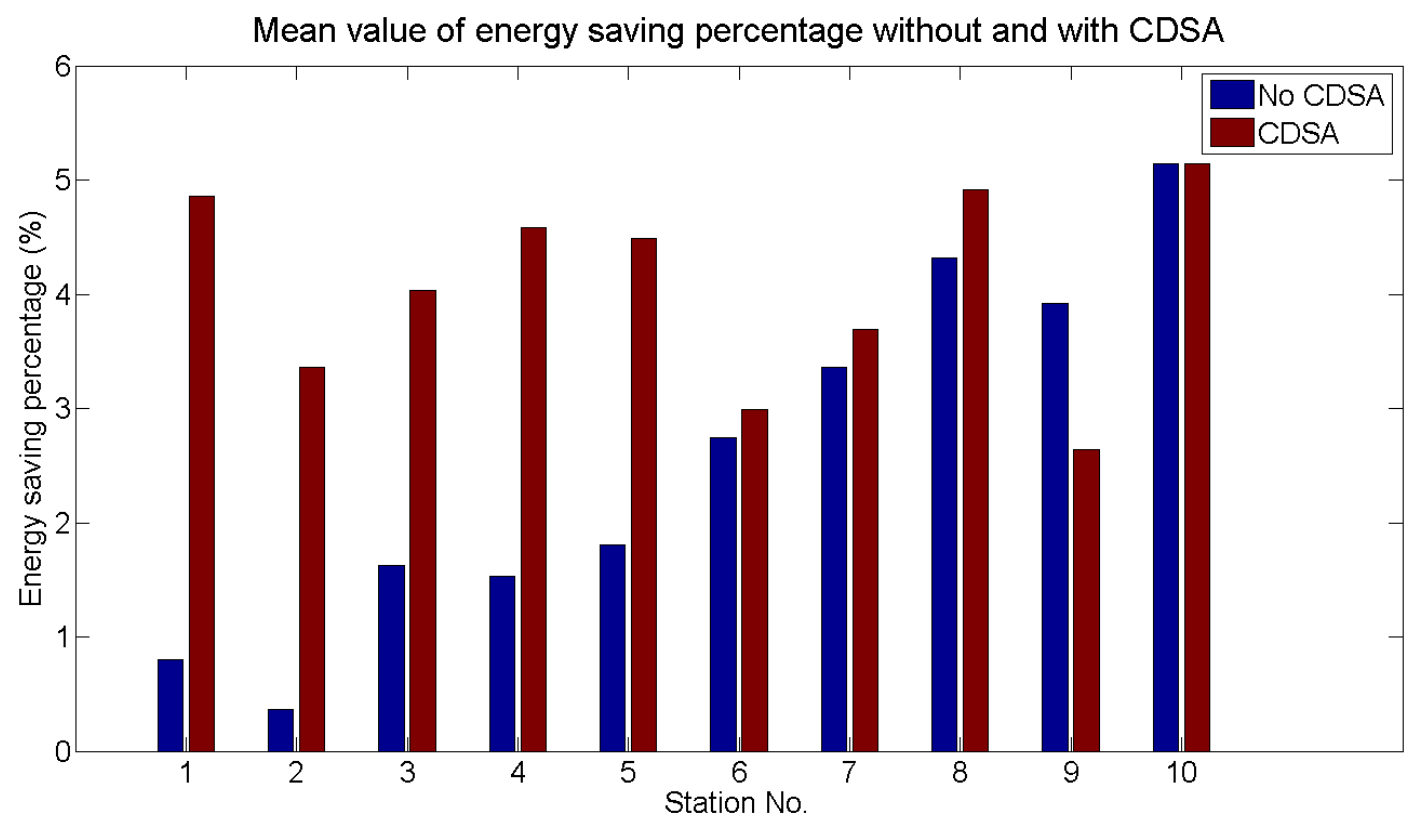

\section{Conclusions}

Metro systems consume huge amounts of energy every day. Saving even a small percentage of this energy consumption can have significant economic growth and environmental protection benefits. For this purpose, a new integrated Energy-efficient Operation Methodology (EOM) of the metro system is proposed in this paper. 
EOM can be divided into two parts. First, to get a system-level energy-saving effect, the Timetable Optimization (TO) method is used. Compared with other methods, TO is a method without additional cost. Instead of storing regenerative braking energy, it rearranges the departure and arrival times of rolling stock so that the energy returned by the braking trains can be consumed simultaneously by those accelerating trains. A genetic algorithm is used to modify the dwell time of every metro train at each stop so as to make full use of the regenerative energy. Then, to solve the problem of disturbance, a novel algorithm named Compensational Driving Strategy Algorithm (CDSA) is proposed in order to save additional energy when disturbances happen. The main idea is to adjust the driving speed and coasting time of the disturbed train in the next several stations after a disturbance so as to fix the incoherence with the optimal timetable and recover the system to energy-saving status as soon as possible.

To validate the correctness and evaluate the energy-saving effect of EOM, a real case of Shanghai Metro Line One (SMLO) is studied. Experiments were done on a test metro train of SMLO. From the experimental data and corresponding data processing, the modeling of the driving strategy is validated. Moreover, the modeling of the traction and braking power of a single metro train is achieved. Based on this, the equivalent circuit model of the metro system is established. A six-station, four-train and bidirectional pilot system is built in Simulink according to the circuit model. Then EOM is specified to the pilot system. The results show that $5.12 \%$ of the total energy is saved in the ideal situation. When a disturbance occurs, only $2.22 \%$ of the total energy can be saved. However, $81.98 \%$ more energy on average can be saved with CDSA. The overall energy-saving effect in real situation is expected to be much more significant since there are many more trains and stations in real metro systems.

The proposed methodology was based on a simplified model of the real metro system. Future work will be focused on how to modify the whole methodology on a more detailed and realistic model. Adding energy-efficient driving into the model may also be concerned. Moreover, how to get the optimal timetable in a real-time level would probably be studied in the future as well.

\section{Nomenclature}

E total energy-consumption of the system

$Q \quad$ number of substations of power supply for the metro system

$U_{j} \quad$ DC voltage of the $j$ th substation

$I_{j} \quad$ DC current of the $j$ th substation

$F_{r} \quad$ running resistance

$L_{n} \quad$ distance between the $n$th and $(n+1)$ th station

$v_{1, n} \quad$ instant speed at the end of accelerating between the $n$th and $(n+1)$ th station

$v_{2, n} \quad$ instant speed at the end of coasting between the $n$th and $(n+1)$ th station

$v_{\max } \quad$ maximal speed of the train

vlimit speed limitation

$a_{1, n} \quad$ acceleration of accelerating between the $n$th and $(n+1)$ th station

$a_{2, n} \quad$ acceleration of coasting between the $n$th and $(n+1)$ th station

$a_{3, n} \quad$ acceleration of braking between the $n$th and $(n+1)$ th station

$t_{\text {start }, n} \quad$ starting time of leaving the $n$th station

$t_{1, n} \quad$ duration of accelerating between the $n$th and $(n+1)$ th station

$t_{2, n} \quad$ duration of coasting between the $n$th and $(n+1)$ th station

$t_{3, n} \quad$ duration of braking between the $n$th and $(n+1)$ th station 
$t_{n} \quad$ total running time between the $n$th and $(n+1)$ th station

$t_{4, n} \quad$ duration of dwelling between the $n$th and $(n+1)$ th station

$t_{\mathrm{d}, n} \quad$ time delay caused by disturbance between the $n$th and $(n+1)$ th station

$t_{\mathrm{cmax}, n} \quad$ maximal compensable time delay between the $n$th and $(n+1)$ th station

$t_{\mathrm{f}} \quad$ total travelling time of the system

\section{Acknowledgments}

This research was supported by the Major State Basic Research Development Program of China (973 Program, grant No. 2014CB046306). The authors would also like to thank Y.M. Yu, J.B. Wang and other engineers of Shanghai Shentong Metro Group Co., Ltd. to set up the research platform to support the experiment.

\section{Author Contributions}

The author Cheng Gong designed all the algorithms and implemented them in Simulink. He also wrote the main part of the manuscript. Author Shiwen Zhang did the experiments on SMLO, did the pre-data processing work and contributed to the modeling improvement and timetable optimization. Author Feng Zhang designed the outline of this paper, checked the results and revised the whole manuscript. Author Jianguo Jiang gave some advice on modeling and data analysis method. Finally, author Xinheng Wang checked the presentation of the paper and did the proofreading.

\section{Conflicts of Interest}

The authors declare no conflict of interest.

\section{References}

1. Shanghai metro. Available online: http://en.wikipedia.org/wiki/Shanghai_metro (accessed on 25 June 2014).

2. González-Gil, A.; Palacin, R.; Batty, P.; Powell, J. A systems approach to reduce urban rail energy consumption. Energy Conver. Manag. 2014, 80, 509-524.

3. Howlett, P.; Milroy, I.; Pudney, P. Energy-efficient train control. Control Eng. Pract. 1994, 2, 193-200.

4. Chevrier, R. An evolutionary multi-objective approach for speed tuning optimization with energy saving in railway management. In Proceedings of the 13th IEEE International Conference on Intelligent Transportation Systems, Funchal, Portugal, 19-22 September 2010; pp. 279-284.

5. Chevrier, R.; Pellegrini, P.; Rodriguez, J. Energy saving in railway timetabling: A bi-objective evolutionary approach for computing alternative running times. Transp. Res. C Emerg. Technol. 2013, 37, 20-41.

6. Howlett, P. The optimal control of a train. Ann. Oper. Res. 2000, 98, 65-87.

7. Howlett, P. Optimal strategies for the control of a train. Automatica 1996, 32, 519-532.

8. Jiaxin, C.; Howlett, P. A note on the calculation of optimal strategies for the minimization of fuel consumption in the control of trains. IEEE Trans. Autom. Control 1993, 38, 1730-1734. 
9. Liu, R.R.; Golovitcher, I.M. Energy-efficient operation of rail vehicles. Trans. Res. A Policy Pract. 2003, 37, 917-932.

10. Khmelnitsky, E. On an optimal control problem of train operation. IEEE Trans. Autom. Control 2000, 45, 1257-1266.

11. Bocharnikov, Y.; Tobias, A.; Roberts, C.; Hillmansen, S.; Goodman, C. Optimal driving strategy for traction energy saving on dc suburban railways. IET Electr. Power Appl. 2007, 1, 675-682.

12. Domínguez, M.; Fernández-Cardador, A.; Cucala, A.P.; Gonsalves, T.; Fernández, A. Multi objective particle swarm optimization algorithm for the design of efficient ato speed profiles in metro lines. Eng. Appl. Artif. Intel. 2014, 29, 43-53.

13. Domínguez, M.; Fernández-Cardador, A.; Cucala, A.P.; Pecharromán, R.R. Energy savings in metropolitan railway substations through regenerative energy recovery and optimal design of ato speed profiles. IEEE Trans. Autom. Sci. Eng. 2012, 9, 496-504.

14. Domínguez, M.; Fernández, A.; Cucala, A.; Lukaszewicz, P. Optimal design of metro automatic train operation speed profiles for reducing energy consumption. Proc. Inst. Mech. Eng. F J. Rail Rapid Transit 2011, 225, 463-474.

15. Lu, S.; Weston, P.; Hillmansen, S.; Gooi, H.B.; Roberts, C. Increasing the regenerative braking energy for railway vehicles. IEEE Trans. Intel. Transp. Syst. 2014, 99, 1-10.

16. Liu, C.; Li, F.; Ma, L.P.; Cheng, H.M. Advanced materials for energy storage. Adv. Mater. 2010, 22, E28-E62.

17. Wang, G.; Zhang, L.; Zhang, J. A review of electrode materials for electrochemical supercapacitors. Chem. Soc. Rev. 2012, 41, 797-828.

18. Burke, A.; Miller, M. The power capability of ultracapacitors and lithium batteries for electric and hybrid vehicle applications. J. Power Sources 2011, 196, 514-522.

19. Hammar, A.; Venet, P.; Lallemand, R.; Coquery, G.; Rojat, G. Study of accelerated aging of supercapacitors for transport applications. IEEE Trans. Ind. Electron. 2010, 57, 3972-3979.

20. Sharma, P.; Bhatti, T.S. A review on electrochemical double-layer capacitors. Energy Convers. Manag. 2010, 51, 2901-2912.

21. Iannuzzi, D.; Tricoli, P. Metro trains equipped onboard with supercapacitors: A control technique for energy saving. In Proceedings of the IEEE International Symposium on Power Electronics Electrical Drives Automation and Motion (SPEEDAM), Pisa, Italy, 14-16 June 2010; pp 750-756.

22. Liu, H.; Jiang, J. Flywheel energy storage-An upswing technology for energy sustainability. Energy Build. 2007, 39, 599-604.

23. Jefferson, C.; Ackerman, M. A flywheel variator energy storage system. Energy Convers. Manag. 1996, 37, 1481-1491.

24. Suzuki, Y.; Koyanagi, A.; Kobayashi, M.; Shimada, R. Novel applications of the flywheel energy storage system. Energy 2005, 30, 2128-2143.

25. Tzeng, J.; Emerson, R.; Moy, P. Composite flywheels for energy storage. Compos. Sci. Technol. 2006, 66, 2520-2527.

26. Bolund, B.; Bernhoff, H.; Leijon, M. Flywheel energy and power storage systems. Renew. Sustain. Energy Rev. 2007, 11, 235-258.

27. Kraytsberg, A.; Ein-Eli, Y. Review on Li-air batteries-Opportunities, limitations and perspective. J. Power Sources 2011, 196, 886-893. 
28. Ellis, B.L.; Nazar, L.F. Sodium and sodium-ion energy storage batteries. Curr. Opinion Solid State Mater. Sci. 2012, 16, 168-177.

29. Mukherjee, R.; Krishnan, R.; Lu, T.-M.; Koratkar, N. Nanostructured electrodes for high-power lithium ion batteries. Nano Energy 2012, 1, 518-533.

30. Kritzer, P. Separators for nickel metal hydride and nickel cadmium batteries designed to reduce self-discharge rates. J. Power Sources 2004, 137, 317-321.

31. Czerwiński, A.; Obrębowski, S.; Rogulski, Z. New high-energy lead-acid battery with reticulated vitreous carbon as a carrier and current collector. J. Power Sources 2012, 198, 378-382.

32. González-Gil, A.; Palacin, R.; Batty, P. Sustainable urban rail systems: Strategies and technologies for optimal management of regenerative braking energy. Energy Convers. Manag. 2013, 75, 374-388.

33. Chen, J.F.; Lin, R.L.; Liu, Y.C. Optimization of an mrt train schedule: Reducing maximum traction power by using genetic algorithms. IEEE Trans. Power Syst. 2005, 20, 1366-1372.

34. Nasri, A.; Moghadam, M.F.; Mokhtari, H. Timetable optimization for maximum usage of regenerative energy of braking in electrical railway systems. In Proceedings of IEEE International Symposium on Power Electronics Electrical Drives Automation and Motion (SPEEDAM), Pisa, Italy, 14-16 June 2010; pp. 1218-1221.

35. Albrecht, T. Reducing power peaks and energy consumption in rail transit systems by simultaneous train running time control. In Computers in Railways IX; WIT Press: Southampton, UK, 2004; pp. 885-894.

36. Fournier, D.; Mulard, D.; Fages, F. Energy optimization of metro timetables: A hybrid approach. In Proceedings of the 18th International Conference on Principles and Practice of Constraint Programming (CP 12), Québec, QC, Canada, 8-12 October 2012; pp. 7-12.

37. Bocharnikov, Y.; Tobias, A.; Roberts, C. Reduction of train and net energy consumption using genetic algorithms for trajectory optimisation. In Proceedings of IET Conference on Railway Traction Systems (RTS 2010), Birmingham, UK, 13-15 April 2010; pp. 1-5.

38. Kim, K.M.; Oh, S.M.; Han, M. A mathematical approach for reducing the maximum traction energy: The case of Korean MRT trains. In Proceedings of the International MultiConference of Engineers and Computer Scientists, Hong Kong, China, 17-19 March 2010; pp. 2169-2173.

39. Peña-Alcaraz, M.; Fernández, A.; Cucala, A.P.; Ramos, A.; Pecharromán, R.R. Optimal underground timetable design based on power flow for maximizing the use of regenerative-braking energy. Proc. Inst. Mech. Eng. F J. Rail Rapid Transit 2012, 226, 397-408.

40. Yang, X.; Ning, B.; Li, X.; Tang, T. A two-objective timetable optimization model in subway systems. IEEE Trans. Intel. Transp. Syst. 2014, 15, 1-9.

41. Li, X.; Lo, H.K. An energy-efficient scheduling and speed control approach for metro rail operations. Transp. Res. B Methodol. 2014, 64, 73-89.

42. Su, S.; Li, X.; Tang, T. A subway train timetable optimization approach based on energy-efficient operation strategy. IEEE Trans. Intel. Transp. Syst. 2013, 14, 883-893.

43. Su, S.; Tang, T.; Li, X.; Gao, Z. Optimization of multitrain operations in a subway system. IEEE Trans. Intel. Transp. Syst. 2014, 15, 673-684.

44. Deep, K.; Singh, K.P.; Kansal, M.; Mohan, C. A real coded genetic algorithm for solving integer and mixed integer optimization problems. Appl. Math. Comput. 2009, 212, 505-518. 
45. Strobel, H.; Horn, P. On energy-optimum control of train movement with phase constraints. Electr. Inform. Energy Techn. J. 1973, 6, 304-308.

46. Albrecht, T.; Oettich, S. A new integrated approach to dynamic schedule synchronization and energy-saving train control. In Computers in Railways VIII; WIT Press: Southampton, UK, 2002; pp. 847-856.

47. Goodman, C. Overview of electric railway systems and the calculation of train performance. In Proceedings of the IET Professional Development course on Electric Traction Systems, Manchester, UK, 3-7 November 2008; pp. 1-24.

48. Goodman, C.; Sin, L. DC railway power network solutions by diakoptics. In Proceedings of the Railroad Conference 1994 ASME/IEEE Joint (in Conjunction with Area 1994 Annual Technical Conference) In IEEE Railroad Conference, Chicago, IL, USA, 22-24 March 1994; pp. 103-110.

49. Hammersley, J.M.; Handscomb, D.C. Monte Carlo Methods; Springer: Berlin, Germany, 1964.

(C) 2014 by the authors; licensee MDPI, Basel, Switzerland. This article is an open access article distributed under the terms and conditions of the Creative Commons Attribution license (http://creativecommons.org/licenses/by/4.0/). 